\title{
Comparing early years and childhood experiences and outcomes in Scotland, England and three city-regions: a plausible explanation for Scottish 'excess' mortality?
}

\author{
Martin Taulbut ${ }^{1 *}$, David Walsh ${ }^{2}$ and John O'Dowd $d^{3,4}$
}

\begin{abstract}
Background: Negative early years and childhood experiences (EYCE), including socio-economic circumstances, parental health and parenting style, are associated with poor health outcomes both in childhood and adulthood. It has also been proposed that EYCE were historically worse in Scottish areas, especially Glasgow and the Clyde Valley, compared to elsewhere in the UK and that this variation can provide a partial explanation for the excess of ill health and mortality observed among those Scottish populations.

Methods: Multiple logistic regression analysis was applied to two large, representative, British birth cohorts (the NCDS58 and the BCS70), to test the independent association of area of residence at ages 7 and 5 with risk of behavioural problems, respiratory problems and reading/vocabulary problems at the same age. Cohort members resident in Scotland were compared with those who were resident in England, while those resident in Glasgow and the Clyde Valley were compared with those resident in Merseyside and Greater Manchester.
\end{abstract}

Results: After adjustment for a range of relevant variables, the risk of adverse childhood outcomes was found to be either no different, or lower, in the Scottish areas. At a national level, the study reinforces the combined association of socio-economic circumstances, parental health (especially maternal mental health) and parenting with child health outcomes.

Conclusion: Based on these samples, the study does not support the hypothesis that EYCE were worse in Scotland and Glasgow and the Clyde Valley. It seems, therefore (based on these data), less likely that the roots of the excess mortality observed in the Scottish areas can be explained by these factors.

Keywords: Child health, Spatial analysis, Social and life-course epidemiology

\section{Background}

Early years' and childhood experiences (EYCE), including socio-economic circumstances, parental health and parenting style, play an important role in determining childhood outcomes, especially social, emotional and mental health, physical health and learning and development. Risk of childhood behavioural problems is increased by factors such as poverty, low educational attainment and housing difficulties, smoking in pregnancy and maternal malaise, as well as low perceived parenting skills [1-4]. Physical

\footnotetext{
* Correspondence: martintaulbut@nhs.net

${ }^{1}$ NHS Health Scotland, Meridian Court, 5 Cadogan Street, Glasgow, Scotland Full list of author information is available at the end of the article
}

health in childhood, including limiting long-term illness and asthma, is associated with poor maternal physical health and low household income [5,6]. Children's cognitive skills (e.g. vocabulary, visual-motor coordination) are also highly correlated with household income [7] as well as maternal educational attainment, poor maternal health, early motherhood and aspects of parenting [6].

EYCE and their associated outcomes can have consequences for health later in life [8]. Beginning with the experiences themselves, analysis of British birth cohort data has found that childhood material disadvantage (such as paternal social class and living in social housing) increases the risk of poor self-reported health, 
smoking and premature mortality in adulthood $[9,10]$. Other research has found that people reporting poor relationships with their parents in childhood and adolescence are more likely to report three or more health problems in adulthood and, in the case of women, have poorer psychological well-being [11,12]. Exposure to adverse child experiences (such as abuse or neglect), problem behaviour in childhood and parental disinterest in their child's education when the child was aged 11, also increases the relative risk of premature death $[13,14]$.

Turning to the outcomes arising from EYCE, childhood social, emotional and mental health (especially conduct disorders) and psychological health disorders have also been found to be associated directly with increased risk of poor adult health, including smoking and worse mental and physical health, in adulthood $[15,16]$. They are also associated with adult determinants of poor health, such as lower educational attainment, reduced economic participation and earnings, relationship difficulties, financial problems and being in trouble with the law $[16,17]$.

Poor childhood physical health appears to increase the risk of poor self-reported general health, respiratory problems and depression in early adulthood [18] and chronic health conditions in older working-age adults (aged 55-65) [19]. In addition to the direct association, childhood morbidity is associated with lower educational attainment and earnings in adulthood [20], which may make a further contribution to adult ill-health.

Finally, childhood cognitive development is associated both indirectly and indirectly with adult health. Lower levels of cognitive development at age seven have been shown to be associated with increased risk of chronic illnesses in adulthood [21]. Higher levels of childhood cognitive development can also lower the risk of poor mental health in adulthood for women (although it may also increase the risk of alcohol abuse for both genders) [22]. Improved childhood learning and development outcomes can also protect adult health indirectly through their association with higher levels of educational attainment, and lower risk of both economic inactivity (for men only) and receipt of welfare benefits in middle-age [23].

Negative early years' and childhood experiences have also been proposed as a possible influence on the 'excess' levels of poor health seen in Scotland, especially in Glasgow and the West Central Scotland conurbation [24]. This 'excess' relates to the higher levels of mortality seen in Scottish areas, even after controlling for age, sex and deprivation. It has been shown to exist for Scotland compared with England [25] and more recently for Glasgow compared with Liverpool and Manchester, where despite these cities sharing identical deprivation profiles, premature mortality is $30 \%$ higher in the Scottish city [26]. Geography of residence (in Scotland compared to England, and Glasgow and surrounds compared to similar English conurbations) therefore seems an important independent influence on rates of adult morbidity and mortality, though the factors driving this difference remain unclear.

Following publication of these studies, a number of hypotheses were proposed, ranging from 'upstream' (e.g. social and economic inequality, deindustrialisation) to 'downstream' explanations (e.g. differences in health behaviours or individual values) [27]. Early years and childhood factors, especially family breakdown, acrimony between partners or dysfunctional parenting, were included among these hypotheses as a 'midstream' explanation. Although these are hard to measure directly, we can measure childhood health and social outcomes associated with negative early years and childhood factors, and include geography of residence alongside wider determinants of health. If this theory is plausible, it might be expected that living in Scottish areas in childhood would also be associated with increased risk of poor childhood outcomes, after adjustment for a range of other relevant variables.

In 2013, the Glasgow Centre for Population Health published a report comparing early years' and childhood experiences in Scotland, England and three 'city-regions' (Glasgow \& the Clyde Valley (GCV), Greater Manchester (GM) and Merseyside) [28]. Its purpose was to investigate whether there were differences in these health determinants that might help explain the poor health of Scotland and GCV relative to these areas. Few clear differences in contemporary childhood and early years' experiences emerged from the analyses. The exceptions were smoking during pregnancy and breastfeeding at a national level, although at a regional level the size of these differences diminished or even disappeared. There were also more ambiguous findings on dysfunctional households, parental warmth and shouting at children. However, the study was descriptive only and did not test for the influence of multiple factors simultaneously on childhood health outcomes.

This paper fills a gap in the knowledge base by formally testing whether historic early years' and childhood experiences were worse in Scotland and GCV compared to other places, all other things being equal. It does this by using more sophisticated statistical methods -multiple logistic regression analysis - to examine the association between geography of residence and child health outcomes, while controlling for a range of important social, economic and family characteristics.

The hypothesis is that the early years' experiences (in particular child poverty, parenting, or some combination of these) for children growing up in Scotland and West Central Scotland was worse compared to children growing up in England, Merseyside and Greater Manchester. This led to poor childhood outcomes, which in turn fed through to poorer adulthood health and higher rates of 
morbidity and premature mortality. In this phase of research the focus is on exploring whether or not residence of Scottish areas in childhood resulted in poorer childhood health outcomes, even after taking other factors into account.

\section{Methods}

Two large cohort studies, the National Child Development Study (NCDS58) and the British Cohort Study 1970 (BCS70), were used to test the hypotheses. It was decided not to use the Millennium Cohort Study (MCS), despite its more comprehensive measures of parenting and health, because its Merseyside sample largely excludes Liverpool City residents and was therefore considered unrepresentative. Essential to this research, both the NCDS58 and BCS70 record cohort members' area of residence (at a national and sub-regional level) at each sweep [29]. Informed consent was obtained from the parents of cohort members for childhood measurements. NCDS58 and BCS70 data are open access datasets available to non-profit research organisations.

\section{Participants}

Only cohort members resident in Scotland or England were selected for the national analyses, providing 14,585 cases in the NCDS58 and 12,323 in the BCS70. For regional comparisons, only cohort members living in Glasgow \& the Clyde Valley, Greater Manchester or Merseyside at ages 7 (NCDS58) and 5 (BCS70) were chosen, with a total of 1,502 NCDS58 cases and 1,247 BCS70 cases. Tables 1 and 2 provide descriptive statistics on the original datasets.

\section{Measures}

\section{Outcome measures}

Three outcome measures, measured at age 7 in the NCDS and age 5 in the BCS70, were derived. These were behavioural problems, respiratory problems and reading/vocabulary problems. The measures were chosen because of their association with negative early years' experiences and with subsequent risk of poor health and disadvantage in adulthood, as discussed above.

Behavioural problems were measured using Rutter scores at ages 5 (NCDS58) and 7 (BCS70). To derive these scores, cohort members' mothers were asked a series of questions describing behaviour shown by many children and asked to what extent these applied to their own child (e.g. child 'is miserable or tearful', 'is squirmy or fidgety', 'prefers to do things on his/her own rather than with other children' (never/sometimes/frequently)). Responses to these questions were then combined into an index used to detect emotional/behavioural disturbances in children [30]. Using an approach described elsewhere [31], cohort members were classified as having normal (below the $80^{\text {th }}$ percentile), moderate $\left(80^{\text {th }}-95^{\text {th }}\right.$ percentile) or severe (above the $95^{\text {th }}$ percentile) behavioural problems. This was then dichotomised into a simple normal $v s$. moderatesevere category. Respiratory problems were defined as the cohort member ever having an asthma attack or bronchitis with wheezing (NCDS58), following Strachan and Butland [32], or having a diagnosis of wheezing, asthma or bronchitis (BCS70). Cognitive ability was measured using the Southgate Group Reading Test (NCDS 1958) and the English Picture Vocabulary Test (BCS70). The Southgate Group Reading test was a measure of word recognition and comprehension. For 16 items, children were asked to look at a picture of an object and circle the word that picture represented; for a further 14, the teacher read out a word and children were again asked to circle the word that applied [33]. Reading problems in the NCDS58 were defined as scoring $0-15$ (out of a possible 30) in the Southgate Group Reading Test at age 7 - one standard deviation below the mean. The English Picture Vocabulary Test was a measure of early English language development and understanding. Children were shown four pictures and a word was read out: they were asked to point to the picture which corresponded to the word being read out [34]. Vocabulary problems in the BCS70 were defined as scoring one standard deviation below the mean in the English Picture Vocabulary Test (EPVT) at age 5.

\section{Explanatory variables}

A range of explanatory variables were also used. Measures covered three themes (socio-economic status (SES), maternal health and parenting) and were selected based in prior research demonstrating their clear association with children's health outcomes [6,35]. SES measures included: father's social class (used as an imperfect proxy for household income), child's birth-weight, age of mother, mother's education, housing tenure, age of mother at birth of the cohort member and (BCS70 only) family structure. Maternal health included measures of smoking in pregnancy, breastfeeding and (for the BCS70 only) maternal mental health. Parenting measures included measures of reading to the child and the role of the father in bringing up the cohort member. With the exception of social class, family structure, reading to child (NCDS only) and role of father (NCDS only), all explanatory variables were treated as dichotomous. Geographic variables showing country (Scotland/England) and region (Glasgow \& the Clyde Valley/Greater Manchester/Merseyside) of residence were also added to the datasets. All explanatory variables were either measured at the same point in time as the outcome measure or shortly after the birth of the cohort member.

\section{Statistical analysis}

In order to check the representativeness of the cohort studies, the social class distribution of these samples, at 
Table 1 Descriptive statistics for relevant explanatory and outcome variables, NCDS 1958

Explanatory variables

Area of residence (aged 7)

England

12945

Scotland

1640

88.8

11.2

Social class of father

Class 1 \& 2

Class 3

2311

8140

2890

Class 4 \& 5

1244

Missing

Low birth weight

Not LBW

9761

LBW

1049

3775

Missing

Mother in school after MLA

Stayed

3455

Not stayed

10553

Missing

\section{Housing tenure}

Owner occupied

Rented

5775

7998

Missing

Age of mother at birth of child

$20+$

Under 20

13284

758

Missing

543

Smoking after 4 months preg.

Non smoker

9267

Smoker

4615

Missing

Ever breastfed

No

Yes

Missing

Father's role in child-rearing

Big, equal to mum

Missing

1243

$\%$

5.2

3.7

63.5

Frequency mum reads to child

Occasionally

14.9

32.8

Every week

45.9

Missing
Leaves mainly to mum

$\%$

46.7

Merseyside

701

26.6

Gr. Manchester

26.8

Class 1 \& 2

11.6

Class 3

54.6

Class $4 \& 5$

26.6

Missing

7.3

Not LBW

64.3

LBW

Missing

7.3

28.4

Stayed

15.3

Not stayed

82.4

Missing

Owner occupied

30.2

Rented

64.7

Missing

5.1

$20+$

Under 20

Missing

5.7

Non smoker

Smoker

Missing

No

Yes

Missing

Big, equal to mum

56.8

Dad sig, mum more

23.2

Leaves mainly to mum

10.2

Missing

9.8
Hardly ever

Occasionally

Every week

Missing
14.5

33.9

45.7

5.9 
Table 1 Descriptive statistics for relevant explanatory and outcome variables, NCDS 1958 (Continued)

\begin{tabular}{|c|c|c|c|c|c|}
\hline \multicolumn{6}{|c|}{ Frequency dad reads to child } \\
\hline Hardly ever & 3762 & 25.8 & Hardly ever & 352 & 23.4 \\
\hline Occasionally & 4676 & 32.1 & Occasionally & 427 & 28.4 \\
\hline Every week & 4783 & 32.8 & Every week & 564 & 37.5 \\
\hline Missing & 1364 & 9.4 & Missing & 159 & 10.6 \\
\hline \multicolumn{6}{|l|}{ Outcome variables } \\
\hline \multicolumn{6}{|l|}{ Rutter scores } \\
\hline Normal & 10689 & 73.3 & Normal & 1164 & 77.5 \\
\hline Moderate-severe & 2258 & 15.5 & Moderate-severe & 208 & 13.8 \\
\hline Missing & 1638 & 11.2 & Missing & 130 & 8.7 \\
\hline \multicolumn{6}{|c|}{ Respiratory problems } \\
\hline No & 12076 & 82.8 & No & 1271 & 84.6 \\
\hline Yes & 2509 & 17.2 & Yes & 231 & 15.4 \\
\hline \multicolumn{6}{|c|}{ Reading problems } \\
\hline No & 11738 & 80.5 & No & 1214 & 80.8 \\
\hline Yes & 2397 & 16.4 & Yes & 236 & 15.7 \\
\hline Missing & 450 & 3.1 & Missing & 52 & 3.5 \\
\hline
\end{tabular}

a national and city-region level, was compared with the 1971 and 1981 Censuses of Population. The social class distribution was found to be similar in both Censuses and cohort studies, increasing the likelihood that findings from these samples also apply to the broader population. Missing values were imputed using the multiple imputation option in SPSS 21. Multiple logistic regression was then used to measure the independent effect of nation and region of residence, on the three outcome measures. Scotland and Glasgow and the Clyde Valley were the reference categories for area of residence. Tables showing both the unadjusted and adjusted effect of area of residence on the three outcome variables were created [Tables 3 and 4]. The unadjusted figures show the effect of area of residence alone on the likelihood of having behavioural problems, respiratory problems or reading/vocabulary problems. Adjusted figures illustrate the effect of area of residence on the outcome measures after adjusting for SES, maternal health and parenting.

As a sensitivity analysis, the process was repeated for those cases for which information was complete for all variables. Results were similar, although the 'complete cases' approach produced slightly higher odds ratios and less precise confidence intervals.

\section{Results}

In the NCDS58, cohort members resident in England at age 7 had an increased risk of behavioural problems (1.36, 1.17 to 1.59$)$, respiratory problems $(1.58,1.36$ to 1.85 ) and reading problems $(2.57,2.15$ to 3.07$)$ at age 7 , even after adjustment for all other explanatory variables, compared with cohort members resident in Scotland.
Cohort members resident in Merseyside or Greater Manchester at age 7 also had an increased risk of behavioural problems, respiratory problems and reading problems, compared with their GCV-resident peers (Table 3). This does not support the hypothesis that living in the Scottish areas is associated with a higher risk of poor childhood outcomes, once other factors are taken into account.

In the BCS70, cohort members resident in England at age 5 had an increased risk of behavioural problems $(1.26,1.06$ to 1.50$)$ and respiratory problems $(1.37,1.14$ to 1.65$)$ at age 5 , after full adjustment, compared with cohort members resident in Scotland at the same age. Country of residence was not a significant predictor of vocabulary difficulties. Region of residence was not significantly associated with any of the three outcomes, after adjusting for SES, maternal health and parenting (Table 4). Again, this fails to confirm the hypothesis that living in Scottish areas was more detrimental to childhood outcomes, all other things being equal.

Taking both sets of results together, it appears that living in Scotland and GCV did not confer 'excess' behavioural problems, respiratory problems or reading/vocabulary problems in childhood. (Indeed, there is a suggestion that residence of Scotland may have provided some modest protective effects). It is difficult to see how EYCE which are better or no different might then translate into higher rates of poor health and mortality in adulthood. Other explanations might be required.

We can also look in more detail at the other determinants of childhood outcomes. At national level, socioeconomic status, maternal health and parenting were all 
Table 2 Descriptive statistics for relevant explanatory and outcome variables, BCS 1970

$\mathrm{N}$

Explanatory variables

Area of residence (aged 5)

England

11157

Scotland

1166

Social class of father
Class $1 \& 2$

Class 3

Class $4 \& 5$

Missing

Low birth weight

Not LBW

LBW

Missing

753

355

Mother's education

Some qualifications

5224

No qualifications

6559

540

Missing

Housing tenure

Owner occupied

Rented

6974

5314

Missing

Age of mother at birth of child

$20+$

Under 20

10866

1027

Missing

430

Smoking during pregnancy

Non smoker

7100

Smoker

4810

Missing

Ever breastfed

No

Yes

Missing

Maternal mental health

Low-moderate malaise

High malaise

Missing

Dad helps mum put child to bed

Yes

10805

1192

326

$942 \quad 15.8$

56.0

19.5

8.7

91.0

6.1

2.9

42.4

53.2

4.4

56.6

43.1

0.3

88.2

8.3

3.5

57.6

39.0

3.4

7575

4631

117

9881

2197

245

No

Missing

0.9

80.2

2.0
9.7

2.6
90.5

9.5

$\%$

\section{.}

(2)

\section{N} $\%$ 302

Merseyside

377

30.2

33.7

Gr. Manchester

450

36.1

Class $1 \& 2$

10.4

Class 3

Class $4 \& 5$

Missing

57.4

26.1

6.1

Not LBW

91.0

LBW

Missing

6.3

2.7

Some qualifications

37.5

No qualifications

56.7

Missing

5.8

Owner occupied

51.6

Rented

48.2

Missing

0.2

$20+$

89.6

Under 20

Missing

8.5

1.9

Non smoker

48.9

Smoker

49.6

Missing

1.5

19

No

885

71.0

Yes

Missing

355

28.5

Low-moderate malaise

950

270

27

21.7

High malaise

Missing

Yes

646

548

51.8

No

Missing

53

43.9

4.3 
Table 2 Descriptive statistics for relevant explanatory and outcome variables, BCS 1970 (Continued)

\begin{tabular}{|c|c|c|c|c|c|}
\hline \multicolumn{6}{|c|}{ Who read to child in last week } \\
\hline Someone & 10805 & 87.7 & Someone & 1062 & 85.2 \\
\hline No one & 1192 & 9.7 & No one & 153 & 12.3 \\
\hline Missing & 326 & 2.6 & Missing & 32 & 2.6 \\
\hline Missing & & & Missing & & \\
\hline \multicolumn{6}{|l|}{ Outcome variables } \\
\hline \multicolumn{6}{|l|}{ Rutter scores } \\
\hline Normal & 9416 & 76.4 & Normal & 944 & 75.7 \\
\hline Moderate-severe & 2260 & 18.3 & Moderate-severe & 248 & 19.9 \\
\hline Missing & 647 & 5.3 & Missing & 55 & 4.4 \\
\hline \multicolumn{6}{|c|}{ Respiratory problems } \\
\hline No & 9823 & 79.7 & No & 1028 & 82.4 \\
\hline Yes & 2475 & 20.1 & Yes & 215 & 17.2 \\
\hline Missing & 25 & 0.2 & Missing & 4 & 0.3 \\
\hline \multicolumn{6}{|c|}{ Vocabulary problems } \\
\hline No & 11000 & 89.3 & No & 1112 & 89.2 \\
\hline Yes & 1323 & 10.7 & Yes & 135 & 10.8 \\
\hline
\end{tabular}

independently associated with the three outcomes. Parenting factors were relatively less important for respiratory problems. Predictors with the strongest association varied by outcome examined. For behaviour problems these included the father's role in bringing up the child, age of mother, social class and mother's mental health. For respiratory problems they included smoking in pregnancy, social class, mother's mental health and low birth-weight. Finally, for reading/vocabulary difficulties these included reading to child, social class and low birth-weight.

Few variables had independent explanatory power at a regional level. This may reflect the similarities between the three regions. Maternal mental health was associated with all three outcomes (BCS70 cohort only), while reading/vocabulary problems were associated with lack of reading to the child and some indicators of socioeconomic status (See Additional file 1).

\section{Discussion}

Based on these two large, representative cohort study samples, the main finding of this study is that the evidence does not support the hypothesis that early years experiences (as measured here) were worse historically in Scotland and GCV, compared to England and Merseyside/ Greater Manchester. After controlling for socio-economic status, maternal health and parenting measures, the childhood outcomes examined in the Scottish areas were either no different, or more favourable, compared to England and its two sub-regions.

The poor health profile in Scotland (and GCV) compared to other European countries is particularly driven by relatively high rates of female lung cancer, male suicide, chronic liver disease (including cirrhosis) and high rates of mortality among younger working-age adults (principally from external causes) [36]. This is relevant because of the links between EYCE and these health

Table 3 Odds ratio for moderate-high Rutter score, respiratory problems and reading problems by area of residence, missing values imputed, NCDS 1958

\begin{tabular}{|c|c|c|c|c|c|c|}
\hline \multirow{2}{*}{$\begin{array}{l}\text { Area } \\
\text { Nation }\end{array}$} & \multicolumn{2}{|c|}{ Odds ratio for moderate-high Rutter score } & \multicolumn{2}{|c|}{ Odds ratio for respiratory problems } & \multicolumn{2}{|c|}{ Odds ratio for reading problems } \\
\hline & Unadjusted OR & Adjusted $O R \neq$ & Unadjusted OR & Adjusted $O R \neq$ & Unadjusted OR & Adjusted $O R \neq$ \\
\hline Scotland & 1 & 1 & 1 & 1 & 1 & 1 \\
\hline \multirow[t]{2}{*}{ England } & $1.32^{*}(1.13-1.53)$ & $1.36^{*}(1.17-1.59)$ & $1.50^{*}(1.29-1.74)$ & $1.58^{*}(1.36-1.85)$ & $2.01^{*}(1.70-2.39)$ & $2.57^{*}(2.15-3.07)$ \\
\hline & $p<0.01$ & $p<0.01$ & $p<0.01$ & $p<0.01$ & $P<0.01$ & $P<0.01$ \\
\hline \multicolumn{7}{|l|}{ City-region } \\
\hline GCV & 1 & 1 & 1 & 1 & 1 & 1 \\
\hline Merseyside & $1.88^{*}(1.29-2.74)$ & $1.75^{* *}(1.17-2.61)$ & $1.60^{*}(1.13-2.24)$ & $1.70 *(1.19-2.44)$ & $2.00^{*}(1.42-2.83)$ & $2.34^{*}(1.60-3.41)$ \\
\hline Gr. Manchester & $2.05^{*}(1.43-2.94)$ & $1.93^{*}(1.32-2.84)$ & $1.64^{*}(1.16-2.30)$ & $1.74^{*}(1.21-2.51)$ & $2.23^{*}(1.59-3.13)$ & $3.06^{*}(2.10-4.46)$ \\
\hline
\end{tabular}

${ }^{*} \mathrm{p}<0.01{ }^{* *} \mathrm{p}<0.05$. $\neq$ Adjusted for socio-economic circumstances, maternal health and parenting. 
Table 4 Odds ratio for moderate-high Rutter score, respiratory problems and vocabulary difficulties by area of residence, missing values imputed, BCS 1970

\begin{tabular}{|c|c|c|c|c|c|c|}
\hline \multirow{2}{*}{$\begin{array}{l}\text { Area } \\
\text { Nation }\end{array}$} & \multicolumn{2}{|c|}{ Odds ratio for moderate-high Rutter score } & \multicolumn{2}{|c|}{ Odds ratio for respiratory problems } & \multicolumn{2}{|c|}{ Odds ratio for vocabulary difficulties } \\
\hline & Unadjusted OR & Adjusted $O R \neq$ & Unadjusted OR & Adjusted $O R \neq$ & Unadjusted OR & Adjusted $O R \neq$ \\
\hline Scotland & 1 & 1 & 1 & 1 & 1 & 1 \\
\hline \multirow[t]{2}{*}{ England } & $1.13(0.96-1.33)$ & $1.26^{* *}(1.06-1.50)$ & $1.24^{*}(1.05-1.45)$ & $1.37^{*}(1.14-1.65)$ & $0.89(0.73-1.07)$ & $0.95(0.77-1.17)$ \\
\hline & $P=N S$ & $P<0.01$ & $p<0.01$ & $p<0.01$ & $p=N S$ & $P<0.01$ \\
\hline \multicolumn{7}{|l|}{ City-region } \\
\hline GCV & 1 & 1 & 1 & 1 & 1 & 1 \\
\hline Merseyside & $1.12(0.79-1.59)$ & $0.80(0.55-1.17)$ & $1.07(0.74-1.55)$ & $1.10(0.74-1.63)$ & $0.68(0.44-1.04)$ & $0.66(0.41-1.06)$ \\
\hline Gr. Manchester & $1.23(0.87-1.73)$ & $0.88(0.63-1.24)$ & $1.04(0.72-1.49)$ & $1.08(0.73-1.60)$ & $0.64(0.42-0.99)$ & $0.67(0.41-1.07)$ \\
\hline
\end{tabular}

${ }^{*} p<0.01 * * p<0.05$. $\neq$ Adjusted for socio-economic circumstances, maternal health and parenting.

outcomes. For example, childhood behavioural problems appear to increase the risk of poor adult mental health, including Malaise and suicide, as well as the likelihood of smoking $[15,16,37,38]$. However, given the results showed no clear excess in negative EYCE in the Scottish areas, they seems a less plausible pathway for increasing adult risk factors associated with the excess morbidity and mortality seen in the Scottish areas.

To the authors' knowledge, this is the first study to test the hypothesis that living in Scotland and Glasgow in the 1960s and 1970s was associated with worse early years experiences and outcomes. It contributes to the existing literature on the 'excess mortality' seen in Scotland and GCV compared to England and comparable English cities and on the factors associated with early years' outcomes. If they are taken at face value, the main findings suggest that key early years' determinants of adult health were no worse in Scotland and GCV, compared to English areas, in the 1960s and 1970s. Unless the 'dose response' (for a population prevalence of behavioural problems, respiratory problems and reading/vocabulary problems) is higher in the Scottish areas, then EYCE seem a less plausible explanation for the poorer health and excess mortality seen relative to England, Greater Manchester and Merseyside.

One contemporary study provides some support for these findings. Dex (2008) used MCS data to explore a limited set of distinctive results for Scottish children born c. 2000/01. Among her findings, she concluded that after adjustment for background variables, risk of problem behaviour and (for one measure) cognitive development, was no different for Scottish children than those living in the rest of the UK [39]. Further confirmation for this is found in a recent survey of the three cities of Glasgow, Manchester and Liverpool, which asked respondents directly about how happy their childhood was and their relationship with their parents. It found little evidence on these measures that Glasgow childhoods were worse compared to the English cities [40]. The findings also reinforce the existing evidence on the combined influence of socio-economic factors, parental health and parenting factors on child outcomes, regardless of geography.

The study has important strengths. It is based on two large, representative samples which have been extensively used by social researchers. While several studies have explored the association between early years' experiences and childhood health outcomes, few have included geography as an independent explanatory variable in this way and none have tested these outcomes at a city-region level. The study is one of the first to do so. It also confirms the important contribution that the combination of socio-economic status, maternal health and parenting can make to childhood outcomes. Even after controlling for parenting skills, material disadvantage still plays a role in determining early years' outcomes [41]. On the other hand, poverty, by itself, does not necessarily lead to poor parenting $[42,43]$.

However, the study also has several limitations. Many of the measures rely on self-report by the parents (usually the mother), with results subject to both intentional (e.g. social desirability) and unintentional (e.g. recall) bias. This could be a particular issue as regards the Rutter scores. The gold standard of validation would be to compare responses to the same set of questions, on the same cohort of children, by parent, teacher and (if possible) child. More subtly, cultural norms could mean that parents from different backgrounds are answering questions in a different way. For example, despite their higher levels of mortality, the proportion of Scottish adults reporting they are in good-health is similar to England [44]. If something similar is also true for the Rutter scores, this could invalidate our assumptions. Lastly, since many of the outcomes and contextual measures were collected around the same point in time, we are unable to identify a causal link - the findings show association only.

The study also sheds little light on whether more extreme aspects of household dysfunction (such as abuse, neglect or parental substance misuse) were more likely to be experienced by children resident in the Scottish areas. 
It has been argued [28] that this is a plausible hypothesis, given higher levels of male imprisonment and opiate use in Scotland and GCV compared to England, Merseyside and Greater Manchester. The importance of this question was underlined by a recent qualitative study [45] conducted with recent Scottish drug injectors, which noted that many had been exposed to childhood trauma. However, this is difficult to test for directly. The NCDS58 and BCS70 cohort studies lack important measures of adverse childhood experiences, notably emotional neglect, sexual abuse and domestic violence. Parenting measures in these studies are much less comprehensive than those available in later cohorts. For example, the Millennium Cohort Survey uses the Pianta Child-parent Relationship Scale [46] to assess warmth and conflict between parent and child, which is not possible in earlier surveys. There are also some doubts about the comparability of measures of looked after children due to the different care systems that operate between countries. Perhaps most importantly, the high level of correlation between adverse childhood experiences (ACE) and disadvantage suggests that children exposed to these traumas are among the least likely to be included in population surveys and most likely to drop out through attrition.

In this context, one way forward might be to adapt the work by Kelly-Irving et al. [47], who used NCDS58 data to derive an adverse childhood experiences (ACE) variable and included it as a predictor of early mortality. While this approach has some limitations, it could be adopted to extend the present study. Such work could also exploit the longitudinal nature of the cohort studies, to investigate the association between early years' experiences (including childhood health outcomes) and the determinants and outcomes of adult health in more detail. A second option might be conduct primary research based on the US ACE studies, in all four countries of the United Kingdom.

\section{Conclusions}

This study does not support the hypothesis that early years' experiences in general were worse in Scotland and GCV. Explanations for the excess poor health seen relative to England and comparable English city-regions may therefore lie elsewhere, though this does not exclude the possibility that more extreme aspects of family dysfunction may be at work in Scotland. This study also reinforces the need for a multifaceted approach for policy-makers interested in improving early years' experiences, including as a means of improving adult health and reducing health inequalities. Regardless of geography, a combination of increasing families' financial resources, improving parental health, especially maternal mental health, and supporting positive parenting (including ensuring fathers play an active role) remain vital to improving childhood outcomes.

\section{Additional file}

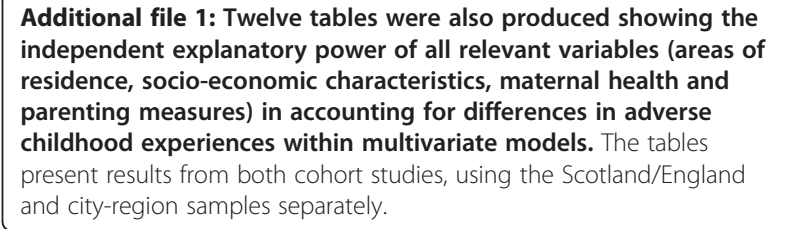

Competing interests

The authors declare that they have no competing interests.

\section{Authors' contributions}

DW conceived of the study, participated in its design and helped to draft the manuscript. JOD participated in the study design and helped to draft the manuscript. MT participated in the study design, carried out the statistical analysis and helped to draft the manuscript. All authors read and approved the final manuscript.

\section{Acknowledgements}

The authors would like to thank Dr Claudia Geue for advice and comments during the analysis process.

The authors are grateful to the Centre for Longitudinal Studies (CLS), Institute of Education for the use of the NCDS 1958 and BCS70 data and to the Economic and Social Data Service (ESDS) for making them available. However, neither CLS nor ESDS bear any responsibility for the analysis or interpretation of these data.

\section{Author details}

${ }^{1}$ NHS Health Scotland, Meridian Court, 5 Cadogan Street, Glasgow, Scotland. ${ }^{2}$ Glasgow Centre for Population Health, House 6, 94 Elmbank Street, Glasgow, Scotland. ${ }^{3}$ University of Glasgow, 1 Lilybank Gardens, Glasgow, Scotland. ${ }^{4} \mathrm{NHS}$ Ayrshire and Arran Health Board, Afton House, Dalmellington Road, Ayr, Scotland.

Received: 2 June 2014 Accepted: 3 October 2014

Published: 10 October 2014

\section{References}

1. Parkes A, Wight D: Growing Up in Scotland: Parenting and children's health. Edinburgh: Scottish Government; 2011.

2. Wilson P, Bradshaw P, Tipping S, Henderson S, 4 Der G, Minnis H: What predicts persistent early conduct problems? Evidence from the Growing Up in Scotland cohort. J Epidemiol Community Health doi:10.1136/jech-2011-200856.

3. Kiernan KE, Huerta MC: Economic deprivation, maternal depression, parenting and children's cognitive and emotional development in early childhood. Br J SOC 2008, 59(4):783-806.

4. Rijlaarsdam J, Stevens GW, van der Ende J, Hofman A, Jaddoe WW, Mackenbach JP, Verhulst FC, Tiemeier H: Economic Disadvantage and Young Children's Emotional and Behavioral Problems: Mechanisms of Risk. J Abnorm Child Psychol 2013, 41(1):125-137. doi:10.1007/s10802-0129655-2.

5. Nikiema B, Spencer N, Seguin L: Poverty and Chronic Illness in Early Childhood: A Comparison Between the United Kingdom and Quebec. Pediatrics 2010, 125:e499. doi:10.1542/peds.2009-0701.

6. Hobcraft J, Kiernan K: Predictive factors from age 3 and infancy for poor child outcomes at age 5 relating to children's development, behaviour and health: evidence from the Millennium Cohort Study, University of York. York: ChiMat; 2010.

7. Cooper K, Stewart K: Does Money affect Children's outcomes? A Systematic Review. York: Joseph Rowntree Foundation; 2013.

8. Graham H, Power C: Childhood disadvantage and adult health: a lifecourse framework. London: Health Development Agency; 2004.

9. Lupton R, Tunstall R, Sigle-Rushton W, Obolenskaya P, Sabates R, Meschi R, Kneale D, Salter E: Growing up in social housing in Britain: A profile of four generations, 1946 to the present day. London: Tenant Services Authority; 2009.

10. Giesinger I, Goldblatt P, Howden-Chapman P, Marmot M, Kuh D, Brunner E: Association of socioeconomic position with smoking and mortality: the contribution of early life circumstances in the 1946 birth cohort. J Epidemiol Community Health 2014, 68:275-279. 
11. Stewart-Brown SL, Fletcher L, Wadsworth MEJ: Parent-child relationships and health problems in adulthood in three UK national birth cohort studies. Eur J Public Health 2005, 15(6):640-646.

12. Huppert FA, Abbott RA, Ploubidis GB, Richards M, Kuh D: Parental practices predict psychological well-being in midlife: Life course associations among women in the 1946 British birth cohort. Psychol Med 2010, 40(9):1507-1518.

13. Felitti VJ: Relationship of Childhood Abuse and Household Dysfunction to Many of the Leading Causes of Death in Adults. Am J Prev Med 1998, 14(4):245-258.

14. Brown DW, Anda RF, Tiemeier H, Felitti VJ, Edwards VJ, Croft JB, Giles WH: Adverse childhood experiences and the risk of premature mortality. Am J Prev Med 2009, 37(5):389-396.

15. Von Stumm S, Deary I, Kivimäki M, Jokela M, Clark H, Batty G: Childhood behaviour problems and health at midlife: 35-year follow-up of a Scottish birth cohort. J Child Psychol Psychiatr published on line February 2011 doi:10.1111/j.1469-7610.2011.02373.x.

16. Colman I, Murray J, Abbott RA, Maughan B, Kuh D, Croudace TJ, Jones PB: (2009) Outcomes of conduct problems in adolescence: 40 year follow-up of national cohort. BMJ 2009, 338:a2981.

17. Goodman A, Joyce R, Smith JP: The Long shadow cast by childhood physical and mental problems on adult life. Proc Natl Acad Sci U S A published ahead of print March 28, 2011, doi:10.1073/pnas.1016970108.

18. Power C, Peckham C: Childhood morbidity and adulthood ill health. J Epidemiol Community Health 1990, 44:69-74.

19. Blackwell DL, Hayward MD, Crimmins EM: Does childhood health affect chronic morbidity in later life? Soc Sci Med 2001, 52(8):1269-1284.

20. Case A, Fertig A, Paxson C: The lasting impact of childhood health and circumstance. J Health Econ 2005, 24(2):365-389. Epub 2005 Jan 5.

21. Martin LT, Fitzmaurice GM, Kindlon DJ, Buka SL: Cognitive performance in childhood and early adult illness: a prospective cohort study. J Epidemiol Community Health 2004, 58:674-679. doi:10.1136/jech.2003.016444.

22. Hatch SL, Jones PB, Kuh D, Hardy R, Wadsworth ME, Richards M: Childhood cognitive ability and adult mental health in the British 1946 birth cohort. Soc Sci Med 2007, 64(11):2285-2296. Epub 2007 Mar 29.

23. Alava MH, Popli G, Hummel S, Chilcott J: Economic outcomes of early years programmes and interventions designed to promote cognitive, social and emotional development among vulnerable children and families. Sheffield: SCHARR; 2011

24. Craig C: The Tears that Made the Clyde. Argyll: Argyll Publishing; 2010.

25. Hanlon P, Lawder RS, Buchanan D, Redpath A, Walsh D, Wood R, Bain M, Brewster DH, Chalmers J: Why is mortality higher in Scotland than in England and Wales? Decreasing influence of socio-economic deprivation between 1981 and 2001 supports the existence of a 'Scottish Effect'. J Public Health 2005, 27(2):199-204.

26. Walsh D, Bendel N, Jones R, Hanlon P: It's not 'just deprivation': why do equally deprived UK cities experience different health outcomes? Public Health 2010, 124(9):487-495.

27. McCartney G, Collins C, Walsh D, Batty D: Accounting for Scotland's excess mortality: towards a synthesis. Glasgow: Glasgow Centre for Population Health; 2011.

28. Taulbut M, Walsh D: Poverty, parenting and poor health: comparing early years' experiences in Scotland, England and three city regions. Glasgow: GCPH; 2013.

29. Eskinmouth C: The British longitudinal birth cohort studies: their utility for the study of health and place. Health Place 1996, 2(1):15-26.

30. Rutter M: A children's behaviour questionnaire for completion by teachers: preliminary findings. J Child Psychol Psychiatr 1967, 8:1-11.

31. Uysal SD: Doubly Robust Estimation of Causal Effects with Multivalued Treatments, Economics Series 297. Vienna: Institute for Advanced Studies. 2013.

32. Strachan DP, Butland BK: Incidence and prognosis of asthma and wheezing illness from early childhood to age 33 in a national British cohort. BMJ 1996, 312:1195.

33. Southgate V: Southgate Group Reading Tests: Manual of Instructions. London: University of London Press; 1962.

34. Brimer MA, Dunn LM: English Picture Vocabulary Test. Bristol: Education Evaluation Enterprises; 1962.

35. Marryat L, Martin C: Growing Up in Scotland: Maternal mental health and its impact on child behaviour and development. Edinburgh: Scottish Government; 2010.
36. Whyte B, Ajetunmobi T: Still the "sick man of Europe"? Scottish Mortality in a European Context, 1950-2010: An analysis of comparative mortality trends. Glasgow: GCPH/ScotPHO; 2012

37. Buchanan A, Flouri $E$, Ten Brinke J: Emotional and behavioural problems in childhood and distress in adult life: risk and protective factors. Aust N Z J Psychiatry 2002, 36(4):521-527.

38. Geoffroy MC, Gunnell D, Power C: Prenatal and childhood antecedents of suicide: 50-year follow-up of the 1958 British Birth Cohort study. Psychol Med 2014, 44(6):1245-1256

39. Dex S: (2008) Millennium Cohort Study exploration of some distinctive results for Scotland. Edinburgh: Scottish Government; 2008.

40. Walsh D, McCartney G, McCullough S, van der Pol M, Buchanan D, Jones R: Exploring potential reasons for Glasgow's excesss mortality: Results of a three-city survey of Glasgow, Liverpool and Manchester. Glasgow: GCPH; 2013.

41. Institute of Education. Improving parenting does not level school playing field. http://www.ioe.ac.uk/48055.html (accessed January 9th 2013)

42. Katz I, Corlyon J, La Placa V, Hunter S: The relationship between parenting and poverty. York: Joseph Rowntree Foundation; 2007.

43. Bulanda RE: Beyond provisions: The relationship between poverty status and parenting among single mothers. Marriage Fam Rev 2008, 42(4):63-87.

44. Bromley C, Shelton N: The Scottish Health Survey: Topic Report UK Comparisons. Edinburgh: Scottish Government; 2010.

45. Scottish Drugs F, Hammersley R, Dalgarno P: "It does kind of make you feel quite numb": Trauma and recovery amongst people who have injected drugs within the past five years. Glasgow: Scottish Drugs Forum; 2013.

46. Driscoll K, Pianta RC: Mothers' and fathers' perceptions of conflict and closeness in parent-child relationships during early childhood. J Early Childhood Infant Psychol 2011, 7:1-24.

47. Kelly-Irving M, Lepage B, Dedieu D, Bartley M, Blane D, Grosclaude P, Lang T, Delpierre C: Adverse childhood experiences and premature all-cause mortality. Eur J Epidemiol 2013, 28:721-734.

doi:10.1186/1471-2431-14-259

Cite this article as: Taulbut et al.: Comparing early years and childhood experiences and outcomes in Scotland, England and three city-regions: a plausible explanation for Scottish 'excess' mortality? BMC Pediatrics 2014 14:259.

\section{Submit your next manuscript to BioMed Central and take full advantage of:}

- Convenient online submission

- Thorough peer review

- No space constraints or color figure charges

- Immediate publication on acceptance

- Inclusion in PubMed, CAS, Scopus and Google Scholar

- Research which is freely available for redistribution 